University of Nebraska - Lincoln

DigitalCommons@University of Nebraska - Lincoln

"You Can Catch More Flies with Honey than Vinegar":

Objectification Valence Interacts with Women's Enjoyment of

Sexualization to Influence Social Perceptions

\author{
Abigail R. Riemer \\ Jill Allen \\ Marco Gullickson \\ Sarah Gervais
}

Follow this and additional works at: https://digitalcommons.unl.edu/psychfacpub

Part of the Personality and Social Contexts Commons, and the Transpersonal Psychology Commons

This Article is brought to you for free and open access by the Psychology, Department of at

DigitalCommons@University of Nebraska - Lincoln. It has been accepted for inclusion in Faculty Publications, Department of Psychology by an authorized administrator of DigitalCommons@University of Nebraska - Lincoln. 


\title{
"You Can Catch More Flies with Honey than Vinegar": Objectification Valence Interacts with Women's Enjoyment of Sexualization to Influence Social Perceptions
}

\author{
Abigail R. Riemer, ${ }^{1}$ Jill Allen, ${ }^{2}$ \\ Marco Gullickson, ${ }^{3}$ \& Sarah J. Gervais ${ }^{3}$ \\ 1 Department of Life Sciences, Carroll University, Waukesha, WI 53186, USA \\ 2 Drake University, Des Moines, IA, USA \\ 3 University of Nebraska-Lincoln, Lincoln, NE, USA \\ Correspondence - Abigail R. Riemer, ariemer@carrollu.edu
}

\begin{abstract}
Although objectification is a common experience for women (Fredrickson \& Roberts, 1997), little is understood about how women perceive sources of objectifying commentary and behaviors. The current work provides a novel integration of objectification and consistency theories to understand how valence of sexual objectification and women's feelings about sexual attention interact to predict perceptions of objectifying sources. In two online vignette studies with 121 and 110 U.S. women recruited through MTurk, female participants were asked to recall an experience of complimentary or critical objectification and report perceptions of source
\end{abstract}

Published in Sex Roles 83 (2020), pp 739-753.

doi:10.1007/s11199-020-01143-z

Copyright (C) 2020 Springer Science+Business Media, LLC. Used by permission.

Published 27 March 2020.

Supplementary material is found following the References. 
warmth, approach behavioral intentions, perceived overlap between the self and the source, and enjoyment of sexualization. Consistent with hypotheses, regression analyses revealed that reporting experiences of complimentary objectification led to more positive source perceptions among women who reported that they enjoy being sexualized relative to reporting experiences of critical objectification. Furthermore, path analyses revealed that self-other overlap emerged as a mechanism of women's more positive source perceptions, with a significant indirect effect of self-other overlap emerging for the link between enjoyment of sexualization and warmth and approach in the complimentary objectification condition. The effects were replicated across two studies. The discussion centers on how understanding women's objectifying source perceptions could illuminate when interpersonal objectification will lead to more experiences of objectification or women's internalization of objectifying self-perceptions.

Keywords: Sexual objectification, Social perception, Gender, Valence, Enjoyment of sexualization

"Chi non ha denaro in borsa, abbia miele in bocca." Italian Proverb (1885)

Centuries of folk wisdom have shed light on what leads a person to initiate, sustain, and deepen a social interaction. As the opening quote notes, one can "catch more flies with honey than vinegar," providing a lens through which to view a person's most treasured relationships being formed through warm, thoughtful, and kind interactions. Countless historical figures have relied on variations of this original proverb, but the intent remains the same: acting in a positive way is bound to draw others near whereas acting in a negative way surely leads to the inverse. Could interpersonal sexual objectification directed toward women, then, sometimes be viewed as a way to draw others near, like "honey" if it was intended as a compliment, or repel them, like "vinegar" if it was intended as a criticism? Women are frequent recipients of body evaluations (e.g., sexual remarks and sexualized gazing) in which they are perceived as nothing more than a body existing for men's consumption (Holland et al. 2017; Kozee et al. 2007; Swim et al. 2001). To be sure, women's experiences are quite different from "flies," yet the parallel among the experiences is apparent in that an instance of sexualization could be perceived as subjectively positive or negative, and this important variation could explain the interpersonal consequences of objectification represented in the literature. 
When women's bodies, or sexualized body parts in particular, are considered by others as capable of representing them, this signifies a particularly insidious form of sexualization known as sexual objectification (Bartky 1990; Fredrickson and Roberts 1997). Sexual objectification that reduces women down to their sexualized body or body parts manifests in behaviors such as commentary focused on a woman's appearance (e.g., catcalling, compliments about sex appeal, criticisms about lack of sex appeal) and sexualized looks (e.g., gazing at a woman's breasts when she is speaking). According to objectification theory, women internalize these experiences and come to view themselves through an objectifying lens, valuing their appearance at the expense of their thoughts, feelings, and desires (Fredrickson and Roberts 1997).

Although literature has revealed many deleterious consequences of sexual objectification, most research has focused on how these experiences shape women's self-perceptions through self-objectification (see Roberts et al. 2018, for review). Fewer studies have examined how women perceive men who objectify them. Understanding how women perceive objectifying sources may help illuminate when experiences of objectification lead women to internalize objectifying selfperceptions or not, as well as whether women will continue or terminate these interactions (Gervais et al. 2018). Thus, in the current work, we examined individual and contextual factors that interact to shape how women perceive sources of objectification.

Given that objectifying interactions reduce women to the status of mere objects, it may be assumed that when objectified, women will perceive men who objectify them uniformly negatively (Teng et al. 2015). While plausible, research also shows that objectified women sometimes engage in greater justification of the system that oppresses them (Calogero 2013), report increased desire to interact with the objectifying source (Gervais et al. 2011), and report enjoying sexualizing experiences (Erchull and Liss 2013; Liss et al. 2011).

To better understand why women may at times view objectification negatively whereas at other times view objectification positively, we apply theorizing from Heider (1958) and other consistency scholars (Festinger 1957; Swann et al. 1989) to examine the nature of these objectifying experiences focusing on objectification valence (Heider 1958). In other words, we examined whether the tone of the 
objectification is more critical or complimentary (Calogero et al. 2009) to help explain these discrepancies in the literature and to illuminate how women perceive those who objectify them. We also consider the way individual differences might fundamentally change the way that the same behavior (e.g., an objectifying gaze) is experienced. Specifically, we argue that enjoyment of sexualization represents a form of objectification sentiment (Heider 1958)-individual differences in the degree to which women like or dislike objectification experiences.

Furthermore, we examined the possibility that objectification valence interacts with objectification sentiment to predict women's perceived source sentiment (Heider 1958), that is, how positively or negatively objectification sources are perceived, specifically in terms of warmth and approach intentions. A plethora of social cognition research has revealed the role of person perception in predicting behavioral responses (for a review see Brewer et al. 1998). For instance, social behaviors are heavily influenced by perceived warmth- perceptions of others' intentions (Fiske et al. 2002). Individuals perceived as high in warmth prompt further interactions whereas those perceived as low in warmth commonly lead to behaviors aimed at terminating interactions (Snyder et al. 1977).

\section{Objectification and Consistency Motives}

Why might one woman perceive an objectifying source positively whereas another does not? Our integration of objectification (Fredrickson and Roberts 1997) and balance (Heider 1958) theories suggests that the answer lies in how women perceive the objectifying experience and whether or not it is consistent with their interest in being sexualized. Human beings attempt to make order in their social worlds, often striving for consistency (a core social motive; Festinger 1957; Heider 1958). According to classic and contemporary social psychological research, inconsistency is a key psychological threat to selfintegrity. As a result, we change our thoughts, feelings, and behaviors in an effort to maintain and restore consistency (e.g., cognitive dissonance theory, Festinger 1957; balance theory, Heider 1958; congruity theory, Osgood and Tannenbaum 1955; self-verification theory, Swann et al. 1989). 
Integrating these classic consistency models with objectification theory, women's consistency motives also may underlie their responses to objectification (Gervais et al. 2018). When women selfobjectify as a result of interpersonal objectification experiences, they adopt a third-person perspective of themselves consistent with an observer's perspective. Instead of considering their thoughts, feelings, and desires, self-objectifying women focus on their observable attributes being considered by a perceiver (e.g., their sex appeal; Fredrickson and Roberts 1997). One interpretation of this self-objectification finding through a cognitive consistency lens is that women change their self-views to be consistent with other people's views of their appearance. When considering how women perceive sources of objectification, it may be essential to consider how women perceive both the objectifying experience in terms of valence and whether the valence is consistent with their sentiment toward objectification.

\section{Objectification Valence}

Experiences of critical objectification may be readily apparent as problematic in the eyes of women because they are perceived as prototypic examples of sexism (Inman and Baron 1996). Disgusted body gazes or commentary suggesting that they need to "lose a few pounds," for example, may clearly demonstrate to women that they are being evaluated negatively through a gendered lens. Similar to how the prototypicality of hostile sexist commentary increases women's ability to label it as sexism (Barreto and Ellemers 2005; Kilanski and Rudman 1998), critical experiences of objectification may be easily identified as such. Although it might be expected that critical experiences of objectification are more detrimental to women, we suggest that the transparency of these experiences assist women in perceiving objectifying sources as less friendly, potentially reducing women's behavioral intentions to interact with objectifying sources.

In comparison, the subjectively positive nature of complimentary objectification suggests that it may operate in more insidious ways. In particular, complimentary objectification may be more difficult for women to label as sexist and be less likely to lead to negative perceptions. To illustrate, findings from a related literature on ambivalent sexism suggest that benevolent sexism (i.e., subjectively positive 
yet restrictive attitudes toward women who conform to gender roles, e.g., "why don't you let me help you, women should not have to carry heavy things") may be more deceptive than hostile sexism (i.e., overt antipathy toward women who violate gender roles, e.g., "why don't you let me do that, women are not very good at math") because benevolent sexism is not seen as a prototypic form of sexism and is therefore regarded as less sexist (Barreto and Ellemers 2005; Riemer et al. 2014). Like benevolent sexism, objectification is theorized as often "masquerading as positively valenced admiration" (Fredrickson and Roberts 1997, p. 178) in the form of complimentary gazes or commentary. Indeed, Riemer et al. (2014) found that benevolent sexism and complimentary objectification were perceived as similarly less sexist than hostile sexism.

We suggest that the valence of objectification could powerfully influence how women perceive those who objectify them. The limited work that has examined valence has focused on the similarly negative consequences of both critical and complimentary objectification (Calogero et al. 2009; Herbozo and Thompson 2006; McLaren et al. 2004; Tantleff-Dunn et al. 1995). Although objectification valence is a discernable variable that should influence social perception, the potentially different consequences of objectification, depending on valence, have been somewhat overlooked in the literature. Furthermore, studies that have introduced objectification in a complimentary manner have revealed different results within valence on social perception. For example, Teng et al. (2015), found that complimentary objectification resulted in a decreased liking of an objectifying source by women, whereas Gervais et al. (2011) found the opposite with women reporting increased desire to interact with an objectifying source following complimentary objectification. In sum, little work has explicitly focused on the effects of objectification valence on social perception, and work that has incidentally included complimentary objectification, has revealed discrepant results.

\section{Objectification Sentiment}

To address this gap in the literature, we suggest that complimentary and critical objectification experiences cannot be considered in isolation. In particular, women are not blank slates when they experience 
objectification in interpersonal interactions. Women instead come to these interactions with different experiences and perspectives about objectification from others. One factor that may influence whether women tend to evaluate objectification more positively (or at least less negatively) is women's enjoyment of sexualization or the extent to which they find appearance-based sexual attention from men positive and rewarding (Liss et al. 2011).

Thus, women may not only consider the valence but also whether the experience of being objectified aligns with their objectification sentiment. For example, complimentary objectification experiences such as approving sexualized gazing or appreciating pick-up lines may be viewed as flattering to some while dehumanizing to others, depending on how women feel about being sexualized. Importantly, although some women may enjoy sexual attention in the form of sexual objectification, this may be dependent upon the type of sexualization they receive. Sexualization can take a seemingly benevolent and admiring tone (e.g., for women who conform to ideals of attractiveness) or a more hostile and derogatory tone (e.g., for women who do not conform to these same ideals). A closer examination of the sought-after experiences on the enjoyment of sexualization scale suggest that women with more positive objectification sentiment may be desiring complimentary (e.g., appearance compliments) rather than critical experiences (e.g., judgmental sexualized gazing, derogatory appearance remarks); however, this important distinction has never, to our knowledge, been explicitly tested.

Although women with positive objectification sentiment may appreciate complimentary objectification, it seems unlikely that women who enjoy sexualization would appreciate and welcome objectification in its more critical form. In contrast, for women who do not enjoy sexualization, experiences of critical or complimentary objectification may be more likely to elicit unfavorable perceptions of the objectifying source because of their negative sentiment toward being sexualized. Thus, although objectification can masquerade as admiration to some women, it is keenly experienced as problematic and leads to negative source sentiment for others, namely those with negative objectification sentiment. Although untested, this notion is consistent with recent work by Gervais et al. (2018) who found that source sentiment was predicted from women's views of themselves and objectification 
valence. The present work extended these considerations and is the first known to examine an individual difference variable related to objectification sentiment-women's enjoyment of sexualization. Gervais et al. also examined objectification specific to a workplace setting, which may differ from sexual objectification that women experience more broadly (e.g., across a variety of professional, social, and interpersonal settings). Thus, the current work examined sexual objectification more broadly.

The work on enjoyment of sexualization focuses primarily on the intrapersonal consequences of perceiving sexual attention positively (Hall et al. 2012; Liss et al. 2011; Moffitt and Szymanski 2011; Nowatzki and Morry 2009), and the current work expands our understanding of these consequences to include interpersonal ramifications. Women who report greater enjoyment of sexualization also report greater endorsement of traditional gender norms, hostile and benevolent sexism, and negative eating attitudes (Liss et al. 2011), suggesting these attitudes lay the foundation for women to tolerate more objectification and interactions with objectifying sources that oppress them. If women who perceive objectification positively continue to seek out interactions with objectifying sources despite the detrimental effects, examining how women perceive sources of objectification may be an essential step toward stopping this vicious cycle. The current work extends and integrates the literature on objectification and enjoyment of sexualization to demonstrate how valence of the experience interacts with women's unique personal attributes to result in a unique set of perceptions.

\section{Overview of the Present Research and Hypotheses}

The current work takes a novel perspective, providing an integration of work on objectification and consistency theories, to understand how the content of sexual objectification and women's feelings about sexual attention interact to predict source perceptions. Source sentiment was assessed, which was operationalized as women's judgments of source warmth (Fiske et al. 2002). Furthermore, we assessed women's behavioral intentions through social distance toward the source (Bogardus 1933) to consider whether source perceptions shape behaviors (Swann et al. 1989). We hypothesized that women's objectification 
sentiment, operationalized as enjoyment of sexualization, would moderate the relation between objectification valence and source perceptions. In particular, complimentary objectification was hypothesized to lead to more positive source perceptions for women high in enjoyment of sexualization relative to women low in enjoyment of sexualization, whereas critical objectification was hypothesized to lead to less positive source perceptions regardless of the extent to which women enjoyed sexualization.

Moreover, because we examined the role of consistency in determining perceptions of objectifying sources, we examined how objectifying valence influenced perceptions of similarity with the objectifying source's perspective as a potential mechanism. Women who received complimentary objectification were expected to perceive more overlap between themselves and the source relative to women who received critical objectification. We also examined whether women's self-objectification-adopting a perspective of the self that is consistent with how others perceive the self (Fredrickson and Roberts 1997)-was a mechanism explaining the links between women's objectification sentiment and source perceptions. As a further test of cognitive consistency, we hypothesized that the relation between objectification sentiment on source perceptions would be mediated by self-other overlap. In particular, more positive objectification sentiment was hypothesized to indirectly lead to more positive source perceptions by increasing self-other overlap, specifically in cases of complimentary, but not critical, objectification. These hypotheses were tested within two experimental studies-Study 1 provided the first test of these ideas and Study 2 provided a direct replication.

\section{Study 1}

In Study 1, we experimentally manipulated valence of objectifying commentary and examined women's social perceptions of the objectifying source depending on objectification sentiment. Study 1 was more exploratory in nature, allowing for an examination of whether openended recall experimental manipulations would prompt reporting of experiences of both complimentary and critical objectification. We also introduced a manipulation of body satisfaction; however, it was not 
effective and therefore is excluded from the analysis presented here (see the supplement for complete information).

\section{Method}

Participants Initially 139 women were recruited from the United States to participate for \$.50 through Amazon's Mechanical Turk; data from 18 participants were excluded from analyses because of failure to correctly answer attention check questions (e.g., to demonstrate you are paying attention, please select 1 "strongly disagree") resulting in a sample of 121 women. We did not conduct a priori power analyses because we were unsure of the effect sizes of the hypothesized effects, but a sensitivity analysis conducted using $\mathrm{G}^{*}$ power (Faul et al. 2009) revealed that with a sample size of 121 participants we had the ability to detect medium-to-large effects $\left(f s=.25^{-.40}\right)$. Participants ranged in age from 18 to $74(M=35.13$ years, $S D=13.24)$, and a majority identified as Caucasian (100, 82.6\%), with the remainder identifying as African American (5, 4.1\%), Asian/Pacific Islander (7, $5.8 \%)$, Hispanic $(8,6.6 \%)$, and another race/ethnicity (1, .8\%). A majority of participants identified as heterosexual (109, 90.1\%), followed by bisexual (9, 7.4\%), gay or lesbian $(1, .8 \%)$ and “other" $(2,1.7 \%)$.

Procedure and Measures Participants were recruited for a study on "Perceptions of Situations, Other People, and Ourselves" through Mechanical Turk. All recruitment methods and procedures were approved by the researchers' Institutional Review Board prior to data collection. Following informed consent, participants were asked to think about or imagine a sexually objectifying experience (adapted from Calogero 2013). To manipulate objectification valence, the prompted recall varied the tone of the objectification. In the complimentary [critical] sexual objectification condition participants read:

Please take a moment to think about or imagine a time when you felt that a man was sexually objectifying you and liked [did not like] what he saw. For example, he was gazing [glaring] at your body or complimenting [criticizing] your body in a sexualized way, making appreciative [unappreciative] sexual comments about your body, or whistling [heckling] at you in public, etc. 
Participants in both conditions were given 5 min and asked to:

think about what took place and describe as many details about the experience (e.g., who was there, what was said or done, how you felt and what you thought, what you did, where you were) as you can in the space below.

Following the completion of the manipulation, participants completed measures indicating sentiment toward the objectifying source, objectification sentiment, and demographics, in this order. Finally, participants were debriefed.

Source Sentiment To assess perceptions of the objectifying source, participants evaluated source warmth (i.e., tolerant, good-natured, sincere, friendly, likable, and trustworthy) on a 1 (not at all) to 5 (extremely) scale (Fiske et al. 2002). Mean warmth scores were created $(\alpha=.97 ; M=2.01, S D=1.16$ ). To assess behavioral intentions, participants completed a seven-item social distance scale (e.g., I would like the man I wrote about in the scenario to move into my neighborhood; I would like to work with the man I wrote about in the scenario in my job) using a 1 (not at all) to 5 (extremely) scale (adapted from Biernat and Crandall 1999; Bogardus 1933). Mean approach intentions were created $(\alpha=.96 ; M=1.52, S D=.99)$ with higher numbers indicating more approach intentions toward the source of the objectifying comment. (Perceptions of source competence were also assessed and are reported in the online supplement.)

Self-Other Overlap Participants were also asked to indicate how close they felt to the man about whom they wrote by choosing one of seven pairs of circles (one representing themselves and the other representing the man), each of which had greater overlap than the previous pair beginning with no overlap (coded as 1 ) to majority overlap (coded as 7) (Aron et al. 1992; see Broccoli 2008; Calogero 2012; Gervais et al. 2018; Puvia and Vaes 2015; $M=1.53$, $S D=1.39$ ).We reasoned that if women were seeing themselves in ways that overlapped and were consistent with the objectifier, then they would report more source closeness. 
Objectification Sentiment How women felt about being sexualized was assessed using the Enjoyment of Sexualization scale (Liss et al. 2011). Participants were asked to indicate the degree to which they enjoyed sexualized attention from men (e.g., "It is important to me that men are attracted to me"; "I feel proud when men compliment the way I look") on a 1 (strongly disagree) to 6 (strongly agree) scale. A mean objectification sentiment score was created $(\alpha=.90 ; M=$ $3.50, S D=1.22$ ) with higher scores indicating more positive objectification sentiment.

Manipulation Checks Participants then completed a manipulation check of the objectifying comment. Participants were asked to think about the comment and indicate how complimentary and critical (reversed) the comment was on a 1 (not at all) to 7 (extremely) scale ( $r=$ .44; $M=3.43, S D=2.26$ ) with higher scores indicating a more positive experience. Using the same scale, participants also indicated the degree to which the interaction with the man was objectifying $(M=5.52$, $S D=1.68)$ and dehumanizing $(M=4.80, S D=2.14)(r=.53, p<.001)$.

\section{Results}

Manipulation Check Perceptions of positivity were submitted to an objectification valence (critical, complimentary) $t$-test that revealed a significant effect of objectification valence on how positive the participant felt the experience was, $t(119)=10.08, p<.0001, d=1.84$. Complimentary objectification was perceived as more positive ( $M=$ 5.03, $S D=1.50)$ than critical objectification $(M=2.29, S D=1.48)$. The complimentary $(M=5.38, S D=1.77)$ and critical $(M=5.68, S D=$ 1.57) objectification conditions were regarded as similarly objectifying, $t(119)=.96, p=.34, d=.18$, but interestingly critical objectification ( $M=5.55, S D=1.69)$ was regarded as more dehumanizing than complimentary objectification $(M=4.15, S D=2.27), t(119)=3.79, p$ $<.001, d=.70$. Objectification sentiment was also submitted to an objectification valence (critical, complimentary) $t$-test revealing no effect of valence on objectification sentiment, $t(119)=.15, p=.88, d=$ .03, meeting the assumption that the moderator is orthogonal to the independent variable (Little et al. 2007). Thus, we examined whether objectification sentiment scores moderated the relation between objectification valence and source sentiment as we hypothesized. 
To gain a deeper understanding of women's experiences of objectification, participants' responses to the objectifying recall prompt were coded for content. Researchers unaware of condition coded each written response for the source and type of experience reported. Sources were coded as "not known to the participant" (e.g., stranger), "known to the participant" (e.g., boyfriend, co-worker, classmate), or "uncodable" (e.g., not mentioned) (Cohen's kappa was calculated as an indicator of inter-rater agreement $\kappa=.90$ demonstrating a strong level of agreement). Type of objectification reported was then coded using the subgroupings of interpersonal objectification on the Interpersonal Sexual Objectification Scale (Kozee et al. 2007) including body gazes (e.g., staring at their body), body evaluation (e.g., whistles walking down the street, sexual remarks), and explicit sexual advances (e.g., touching, sexual gestures) (Cohen's kappa was calculated for each category as an indicator of inter-rater agreement: gazes $\kappa=.74$, evaluations $\kappa=.83$, unwanted sexual advances $\kappa=.79$, demonstrating moderate-to-strong levels of agreement). As indicated by the frequencies and resulting percentages of each objectification source and type reported in Table 1a, a majority of participants recalled an experience with an unknown male source and primarily recalled instances of body evaluations and body gazes.

Table 1 Coded content of reported objectification experiences

$\begin{array}{rrr}\text { Entire } & \text { Complimentary } & \begin{array}{r}\text { Critical } \\ \text { Condition }\end{array} \\ n(\%) & n(\%) & n(\%)\end{array}$

(a) Study 1

Objectification source

Known other

$38(36.19 \%) \quad 19(29.23 \%) \quad 19(33.93 \%)$

Unknown other

$67(60.91 \%)$

$39(60.00 \%) \quad 28(50.00 \%)$

Type of objectification

Body gazes

$37(34.00 \%)$

$20(30.77 \%) \quad 17(30.36 \%)$

Body evaluations

$72(65.45 \%)$

$38(58.46 \%) \quad 34(60.71 \%)$

Sexual advances

$38(34.54 \%)$

$21(32.30 \%) \quad 16(28.57 \%)$

(b) Study 2

Objectification source

Known other

$37(35.92 \%)$

$17(28.81 \%) \quad 20(39.22 \%)$

Unknown other

$62(60.19 \%)$

$39(66.10 \%) \quad 23(45.10 \%)$

Type of objectification

Body gazes

$24(23.30 \%)$

$16(27.12 \%) \quad 8(15.69 \%)$

Body evaluations

$71(68.93 \%)$

$36(61.02 \%) \quad 35(68.63 \%)$

Sexual advances

$40(38.83 \%)$

$29(49.15 \%) \quad 11(21.57 \%)$ 
Preliminary Hypothesis Testing To assess whether objectification valence affected source sentiment, all dependent variables were first submitted to independent samples $t$-tests. Moreover, to examine whether objectification sentiment moderated the relation between objectification valence and source sentiment, all dependent measures were submitted to separate hierarchical multiple regression models. Objectification sentiment (mean-centered, $M=3.50, S D=1.22$ ) and objectification valence (dummy coded, o = critical, $1=$ complimentary) were entered in Step 1 and the objectification sentiment $\mathrm{x}$ objectification valence interaction was entered in Step 2.

Source warmth. An independent samples $t$-test revealed a main effect of condition on perceived source warmth, $t(115.72)=-3.91, p<.001, d$ $=.71$ (see Table 2a). As expected, women in the complimentary objectification condition perceived the objectifying source as warmer $(M=$ $2.37, S D=1.25$ ) than women in the critical objectification condition $(M=1.60, S D=.90)$. Furthermore, consistent with hypotheses, Step 2 of the model was significant on perceived source warmth. Given our hypotheses, we compared simple slopes (Aiken and West 1991) for objectification sentiment and warmth separately for critical and complimentary objectification by comparing condition differences at higher $(+1 S D)$ and lower $(-1 S D)$ levels of objectification sentiment (and applying a Bonferroni correction of .05/2 = .025). As expected, objectification sentiment positively predicted warmth in the complimentary objectification condition ( $b=.29, S E=.11, t=2.66, p=.009$ ), but it was unrelated to warmth in the critical objectification condition $(b=$ $-.02, S E=.12, t=-.20, p=.84)$. Moreover, the difference between complimentary and critical objectification was significant at higher $(b$ $=1.16, S E=.28), t(117)=-4.15, p<.0001$, but not lower $(b=-.39$, $S E=.28), t(117)=-1.38, p=.17$, levels of objectification sentiment.

Behavioral Intentions A main effect of condition emerged on approach behavioral intentions, $t(90.04)=-3.35, p=.001, d=.59$ (see Table $2 \mathrm{~b}$ ). Women in the complimentary objectification condition reported more approach behavioral intentions toward the objectifying source $(M=1.78, S D=1.20)$ relative to women in the critical objectification condition $(M=1.23, S D=.52)$. Importantly, Step 2 of the regression model was also significant on behavioral intentions. Again 


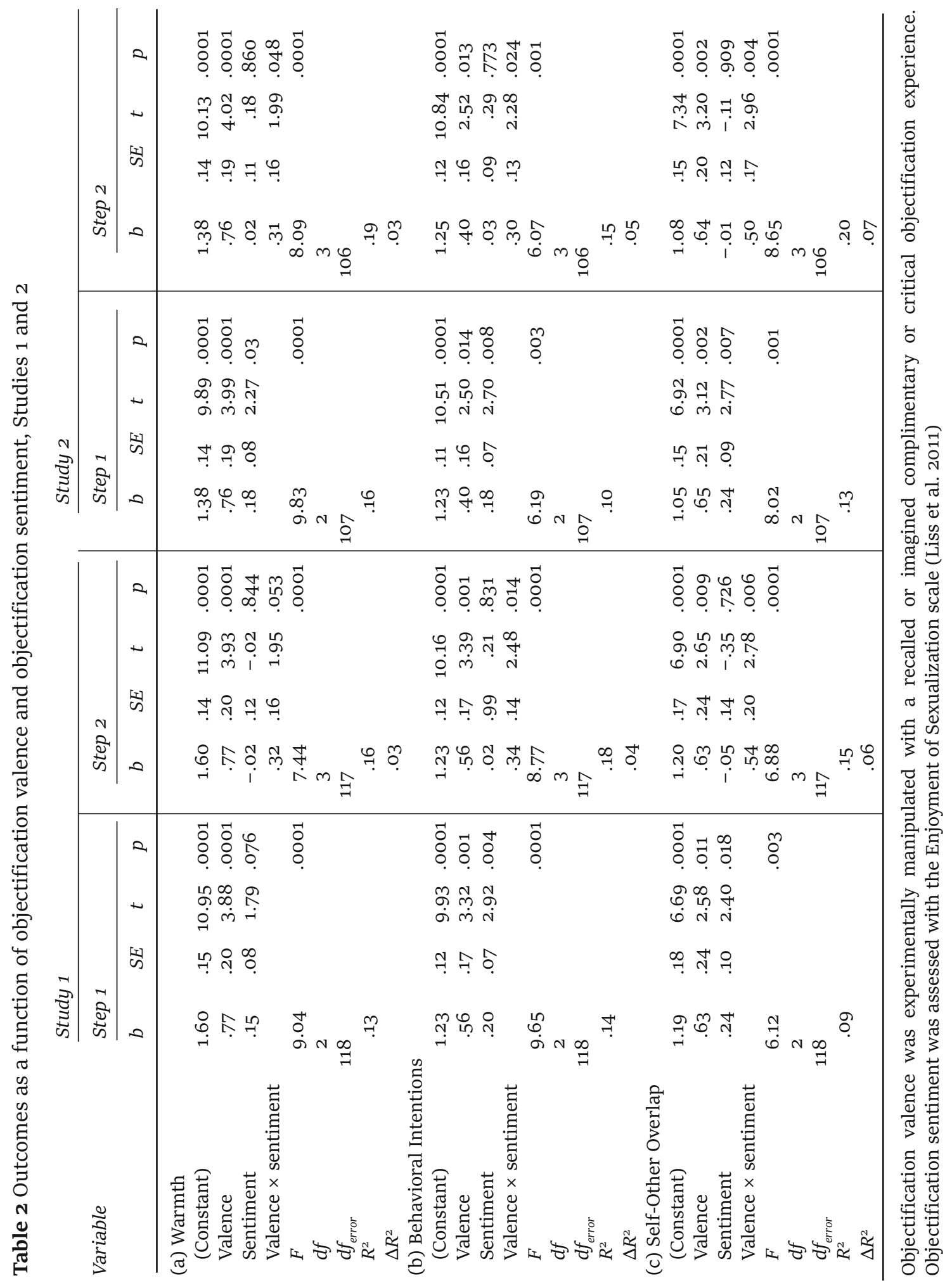


comparing condition differences at higher $(+1 S D)$ and lower $(-1 S D)$ levels of objectification sentiment, objectification sentiment positively predicted approach intentions in the complimentary objectification condition ( $b=.36, S E=.09, t=3.88, p<.0001)$, but it was unrelated to approach intentions in the critical objectification $(b=.02, S E$ $=.10, t=.21, p=.83)$. Additionally, the difference between complimentary and critical objectification on approach behaviors was significant at higher $(b=-.97, S E=.23), t(117)=-4.15, p<.0001$, but not lower $(b=-.15, S E=.23), t(117)=-.63, p=.53$, levels of objectification sentiment.

Self-Other Overlap Extending source sentiment to an indicator of self-other overlap, an independent samples $t$-test revealed a main effect of condition on perceived self-other overlap, $t(86.66)=-2.63, p$ $=.01, d=.47$ (see Table $2 \mathrm{c}$ ). In line with expectations, women in the complimentary objectification condition perceived more self-other overlap with the objectifying source $(M=1.82, S D=1.74)$ than women in the critical objectification condition $(M=1.20, S D=.70)$. Moreover, Step 2 of the model was significant on self-other overlap. Consistent with hypotheses, comparing condition differences at higher $(+1 S D)$ and lower $(-1 S D)$ levels of objectification sentiment, objectification sentiment positively predicted self-other closeness in the complimentary objectification condition $(b=.49, S E=.13, t=3.70, p<.0001)$, but it was unrelated to self-other overlap in the critical objectification condition $(b=-.05, S E=.14, t=-.35, p=.73)$. Additionally, the difference between complimentary and critical objectification on selfother closeness was significant at higher $(b=-1.29, S E=.34), t(117)$ $=-3.83, p<.001$, but not lower $(b=.03, S E=.34), t(117)=.10, p=$ .92 , levels of objectification sentiment.

\section{Indirect Effect of Objectification Sentiment on Source Perceptions}

We also examined the conditional indirect effects of objectification sentiment on source sentiment via self-other overlap for women in the complimentary versus critical objectification condition. Parallel moderated mediation models were run with objectification sentiment as the predictor, self-other overlap as the mediator, objectification condition as the moderator between objectification sentiment and selfother overlap, and source sentiment (warmth, approach intentions) 
as the outcomes using Hayes's (2018) SPSS Process macro (Model 7). A bootstrap approach (Shrout and Bolger 2002), which maximizes power while minimizing Type I error, was implemented. Bootstrapping provides an empirical approximation of sampling distributions of indirect effects to produce confidence intervals (CI) to assess the significance of indirect effects (Williams and MacKinnon 2008); an indirect effect is significant and indicates mediation if the 95\% confidence interval does not contain zero (see Mallinckrodt et al. 2006). We performed a nonparametric resampling method (bias-corrected bootstrap) with 10,000 resamples drawn to derive the $95 \% \mathrm{CI}$ for the indirect effects.

In both models, the interaction between objectification condition and objectification sentiment as a predictor of self-other overlap was significant, suggesting the effect of objectification sentiment on selfother overlap is conditional on the valence of the objectification (see Fig. 1). The unique effect of objectification sentiment on self-other overlap was present in the complimentary objectification condition, but not the critical objectification condition. In other words, women's objectification sentiment positively predicted self-other overlap in instances of complimentary, but not critical objectification.

Finally, we examined the indirect effects of objectification sentiment on warmth and approach behaviors via self-other overlap for complimentary versus critical objectification. In the critical objectification condition, the 95\% CIs for the conditional indirect effect of objectification sentiment on warmth [-.0749, .3751] (see Fig. 1a) and approach behaviors [-.1011, .0384] (see Fig. 1b) contained zero. But, in the complimentary objectification condition, the $95 \%$ CIs for the conditional indirect effect of objectification sentiment on warmth [.0742, .3751] and approach behaviors [.0918, .4766] did not contain zero. This means that consistent with hypotheses, objectification sentiment indirectly led to more positive source sentiment through an increased perception of similarity with the source when women reported experiencing complimentary objectification; however, source sentiment was not indirectly (or directly) influenced by objectification sentiment when women reported experiencing critical objectification. 


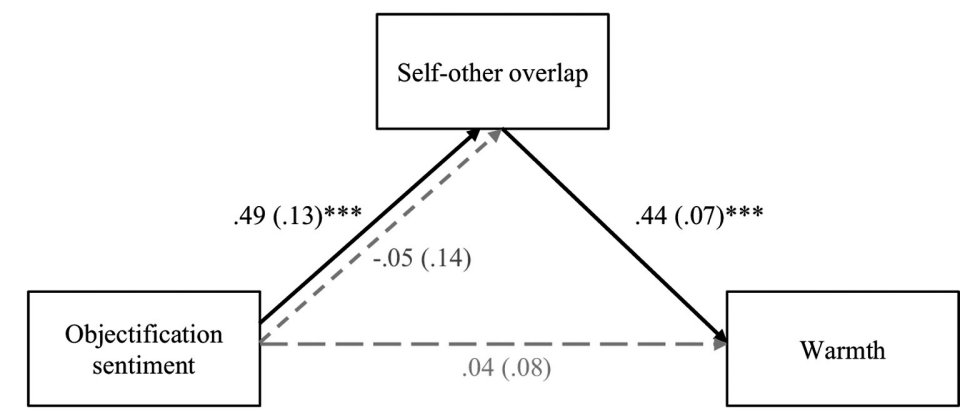

(a) Mediation model predicting source warmth

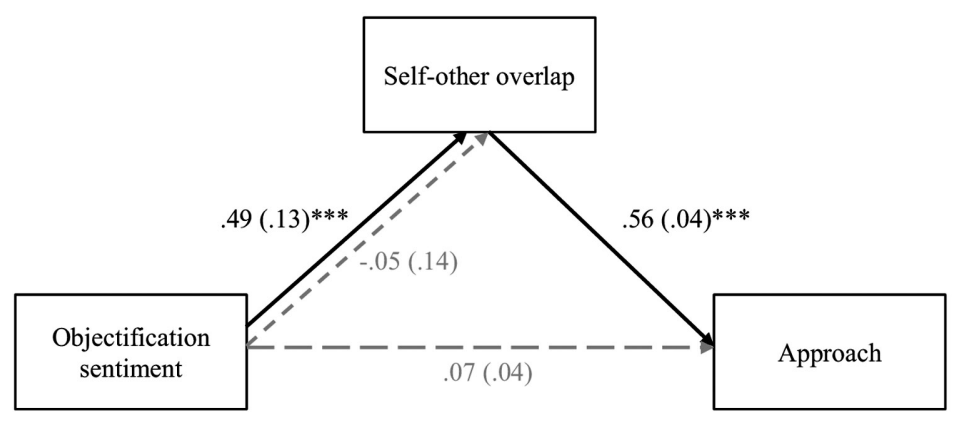

Fig. 1 Study 1 mediation analyses for the indirect effect of objectification sentiment on (a) perceived source warmth and (b) approach behavioral intentions through self-other overlap by condition. Unstandardized coefficients (standard errors). The values of the relation from objectification sentiment to self-other overlap outside the triangle represent the model in the complimentary objectification condition and the values inside the triangle represent the model in the critical objectification condition $* * * p<.001$

\section{Discussion}

The results from Study 1 revealed that women's perceptions of an objectifying source can be predicted by the valence of the experience and her feelings about being sexualized. Although critical objectification predicted less positive sentiment toward an objectifying source, for women with more positive objectification sentiment, more complimentary experiences of objectification predicted more positive sentiment toward an objectifying source. Moreover, women's objectification sentiment positively predicted perceptions of self-other overlap when experiencing complimentary, but not critical objectification, and self-other overlap emerged as a mediating mechanism of the relation between objectification sentiment and positive source perceptions. 


\section{Study 2}

Although Study 1 provided unique insight into the factors that shape women's perceptions of objectifying sources, Study 1 contained a failed manipulation of body sentiment (see the online supplement). It appears that this manipulation did not affect the pattern of results observed, but we conducted a replication attempt without this manipulation in Study 2 to ensure that this was indeed the case. Thus, Study 2 consisted of direct replication of Study 1 without the failed manipulation to echo best practices in the field for increasing reproducibility and replication (Earp and Trafimow 2015).

\section{Method}

Participants Based on effect size estimates from Study 1, an a priori power analysis revealed that the required sample size to detect the objectification valence by objectification sentiment interaction in the present study ranged from 62 to 76 participants (Faul et al. 2009). To potentially account for unusable data (e.g., participants who failed to pass attention checks), 130 women were recruited from the United States for \$.50 through Amazon's Mechanical Turk; 20 participants were excluded from analyses for failing to pass attention checks leaving a sample of 110 women. Participants ranged in age from 20 to 67 $(M=4.29, S D=12.68)$ and the majority identified as Caucasian (92, 83.6\%), followed by African American (11, 10\%), Hispanic (3, 2.7\%), Asian/Pacific Islander (1,.9\%), or another race/ethnicity (3, 2.7\%). A majority of participants identified as heterosexual (102, 92.7\%), followed by bisexual $(5,4.5 \%)$, or another sexual orientation $(3,2.7 \%)$.

\section{Procedure and Measures}

The procedure replicated that of Study 1, except we did not include the (failed) manipulation of body sentiment from Study 1. Like in Study 1, written experiences of objectification were coded for the source and type of experience reported. As reported in Table 1b, women reported similar frequencies to those reported in Study 1. All procedures were approved by the researchers' Institutional Review Board prior to the start of data collection. 
The same measures of warmth $(\alpha=.95 ; M=1.79, S D=1.07)$, behavioral intentions $(\alpha=.96 ; M=1.45, S D=.88)$, self-other overlap ( $M=$ $1.40, S D=1.15)$, and objectification sentiment $(\alpha=.89 ; M=3.46, S D$ $=1.20$ ) were used. Moreover, the same manipulation checks were used to assess how positive ( $r=.43 ; M=3.74, S D=1.98)$, as well as objectifying $(M=5.47, S D=1.83)$, and dehumanizing $(M=5.15, S D=2.01)(r$ $=.44, p<.001)$, participants perceived their interaction with the man.

\section{Results}

Manipulation Check Perceptions of positivity were submitted to a objectification valence (critical, complimentary) $t$-test which revealed a significant effect of objectification valence on how positive the participant felt the experience was, $t(108)=7.04, p<.0001, d=1.35$, with reported experiences of complimentary objectification perceived more positively $(M=4.76, S D=1.58)$ than reported experiences of critical objectification $(M=2.55, S D=1.71)$. The complimentary $(M=5.64$, $S D=1.60)$ and critical $(M=5.27, S D=2.07)$ objectification conditions were regarded as similarly objectifying, $t(107)=1.03, p=.30, d=.20$, but again critical objectification $(M=5.57, S D=4.78)$ was regarded as more dehumanizing than complimentary objectification $(M=4.78$, $S D=2.09), t(108)=2.09, p=.04, d=.40$. Objectification sentiment was also submitted to an objectification valence (critical, complimentary) $t$-test, revealing no effect of objectification valence, $t(108)=.90$, $p=.37, d=.17$, allowing for the examination of objectification sentiment as a potential moderator between objectification valence and source sentiment. Similar to Study 1, responses were coded for perpetrator and experience reported (Cohen's kappa was calculated to demonstrate inter-rater agreement for each categorical coding: source $\kappa$ $=.92$, gazes $\kappa=.81$, evaluations $\kappa=.83$, unwanted sexual advances $\kappa=.79$ demonstrating moderate-to-strong levels of agreement) and can be found in Table $1 \mathrm{~b}$.

Hypothesis Testing Using the same analytic approach as Study 1, the main effect of condition on source sentiment was assessed using an independent samples $t$-test. To assess whether objectification sentiment moderated this relation, dependent variables were submitted to separate hierarchical multiple regressions in which objectification 
sentiment (mean-centered, $M=3.46, S D=1.20$ ) and objectification valence (dummy coded, $\mathrm{o}=$ critical, $1=$ complimentary) were entered in Step 1 and the objectification sentiment $\mathrm{x}$ objectification valence interaction was entered in Step 2.

Source Warmth An independent samples $t$-test revealed a main effect of condition on perceived source warmth, $t$ (93.73) $=-3.74, p<$ $.001, d=.72$ (see Table 2a). Women in the complimentary objectification condition perceived the objectifying source as warmer $(M=2.12$, $S D=1.23)$ than women in the critical objectification condition $(M=$ $1.40, S D=.69$ ). Consistent with hypotheses, Step 2 of the model was significant on source warmth (see Fig. 2a). Comparing condition differences at higher $(+1 S D)$ and lower $(-1 S D)$ levels of objectification sentiment revealed that objectification sentiment positively predicted warmth in the complimentary objectification condition $(b=.33, S E=$ $.11, t=3.04, p=.003)$, but it was unrelated to warmth in the critical objectification condition $(b=.020, S E=.11, t=.18, p=.86)$. Moreover, the difference between complimentary and critical objectification was significant at higher $(b=1.14, S E=.26), t(106)=4.28, p<$ .0001 , but not lower $(b=.38, S E=.26), t(106)=1.43, p=.16$, levels of objectification sentiment.

Behavioral Intentions A main effect of condition on approach behavioral intentions emerged, $t(94.69)=-2.17, p=.03, d=.41$ (see Table $2 \mathrm{~b}$ ), with women in the complimentary objectification condition reporting more approach behavioral intentions toward an objectifying source $(M=1.53, S D=.95)$ relative to women in the critical objectification condition $(M=1.21, S D=.55)$. Step 2 of the model was significant on approach behavioral intentions (see Fig. 2b). Comparing condition differences at higher $(+1 S D)$ and lower $(-1 S D)$ levels of objectification sentiment, objectification sentiment positively predicted approach intentions in the complimentary objectification condition ( $b$ $=.33, S E=.09, t=3.57, p=.0005)$, but it was unrelated to approach intentions in the critical objectification condition $(b=.03, S E=.09$, $t=.29, p=.77$ ). Additionally, the difference between complimentary and critical objectification on approach intentions was significant at higher $(b=.76, S E .22), t(106)=3.41, p=.0009$, but not lower $(b=$ $.04, S E .22), t(106)=.17, p=.86$, levels of objectification sentiment. 


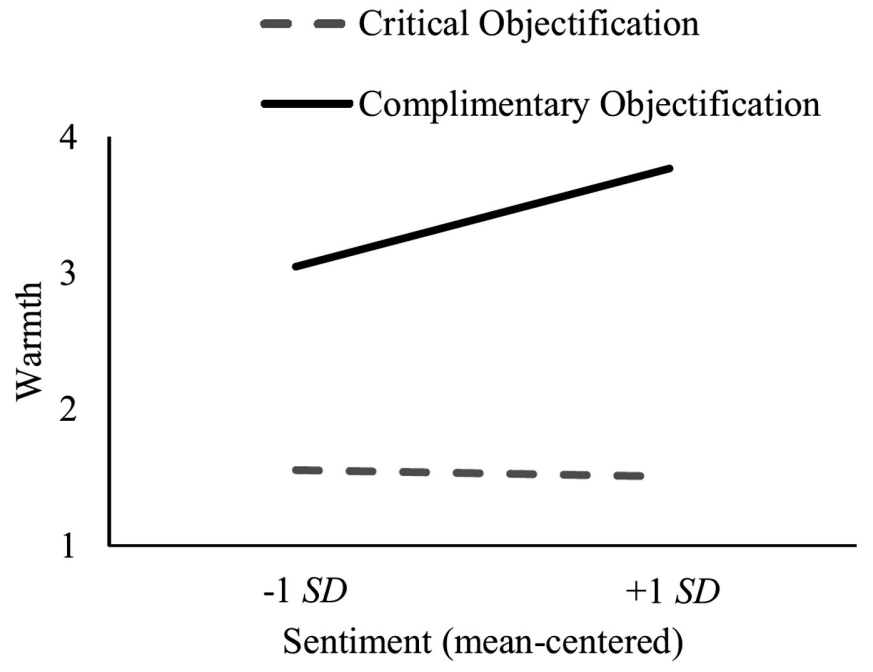

(a) Predicting perceived source warmth

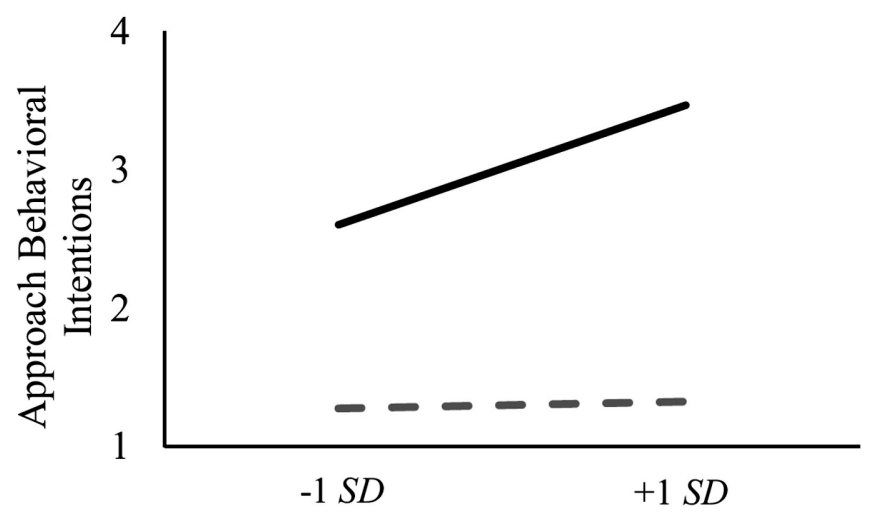

Sentiment (mean-centered)

(b) Predicting approach behavioral intentions

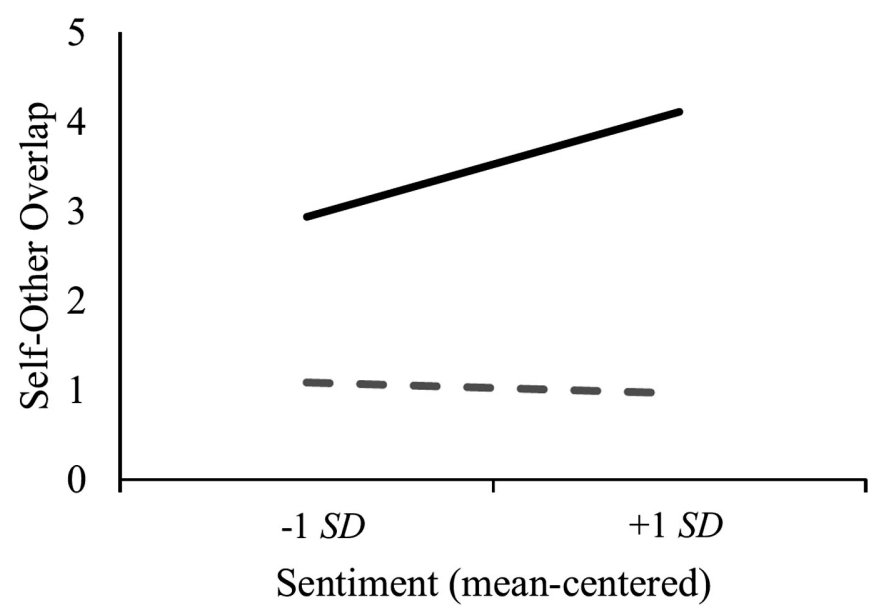

Fig. 2 Interactive effect of objectification valence and objectification sentiment level predicting (a) perceived source warmth, (b) approach behavioral intentions, and (c) selfother overlap in study 2 . Objectification valence was experimentally manipulated with a recalled or imagined complimentary or critical objectification experience.

Objectification sentiment was assessed with the enjoyment of Sexualization scale (Liss et al. 2011). The solid lines indicate significant slopes $(p<.05)$ whereas the dashed lines indicate nonsignificant relationships 
Self-Other Overlap An independent samples $t$-test revealed a main effect of condition on perceived self-other overlap, $t(64.81)=-3.00$, $p=.004, d=.56$ (see Table 2c). Specifically, women in the complimentary objectification perceived more self-other overlap with the objectifying source $(M=1.68, S D=1.49)$ than women in the critical objectification condition $(M=1.08, S D=.34)$. Moreover, Step 2 of the model was significant on self-other overlap (see Fig. 2c). Comparing condition differences at higher $(+1 S D)$ and lower $(-1 S D)$ levels of objectification sentiment, objectification sentiment positively predicted self-other closeness in the complimentary objectification condition ( $b$ $=.48, S E=.12, t=4.12, p=.0001$ ), but it was unrelated to self-other overlap in the critical objectification condition $(b=-.01, S E=.12, t$ $=-.11, p=.91$ ). Additionally, the difference between complimentary and critical objectification on self-other closeness was significant at higher $(b=1.23, S E .28), t(106)=4.38, p<.0001$, but not lower $(b=$ $.05, S E .29), t(106)=.17, p=.86$, levels of objectification sentiment.

\section{Indirect Effect of Objectification Sentiment on Source Perceptions}

The same analyses used in Study 1 were again used to test hypotheses examining the conditional indirect effects of objectification sentiment on source sentiment via self-other overlap for women in the complimentary versus critical objectification condition. The interaction between objectification condition and objectification sentiment as a predictor of self-other overlap was significant (see Fig. 3), meaning objectification sentiment conditionally affects self-other overlap. The unique effect of objectification sentiment on self-other overlap was present in the complimentary objectification condition, but not the critical objectification condition. Like in Study 1, objectification sentiment positively predicted self-other overlap when women reported experiencing complimentary, but not critical objectification.

Again, we examined the indirect effects of objectification sentiment on warmth and approach behavioral intentions via self-other overlap for complimentary versus critical objectification conditions. Like in Study 1, the 95\% CIs for the conditional indirect effect of objectification sentiment on warmth $[-.0481$, .0212] (see Fig. 3a) and approach behaviors [-.0419, .0193] (see Fig. 3b) in the critical objectification condition contained zero. But the 95\% CIs for the conditional indirect effect of objectification sentiment on warmth [.0699, .5624] 


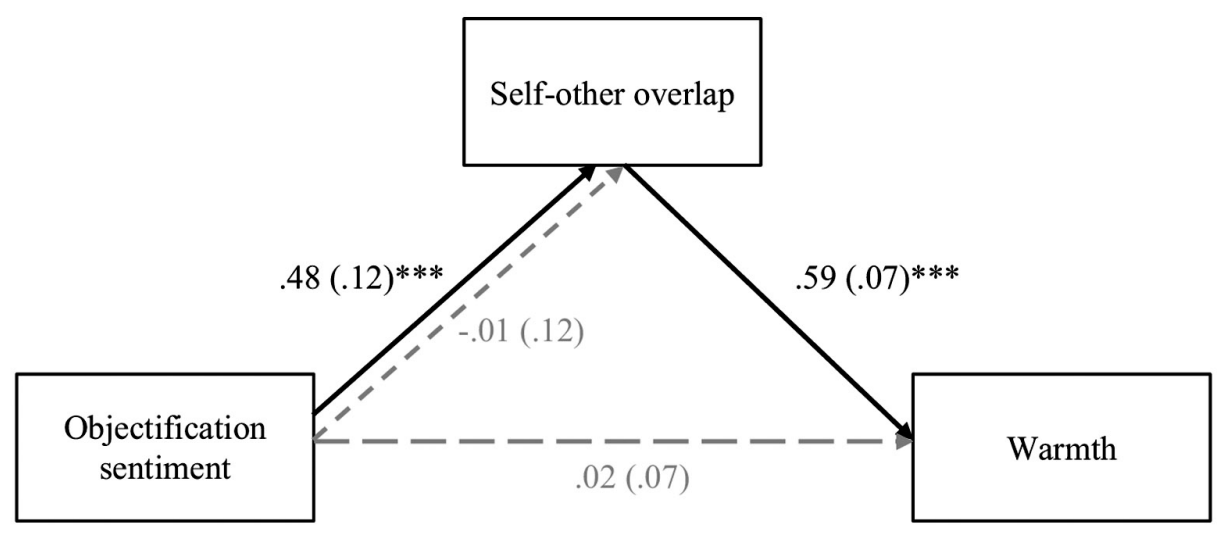

(a) Mediation model predicting source warmth

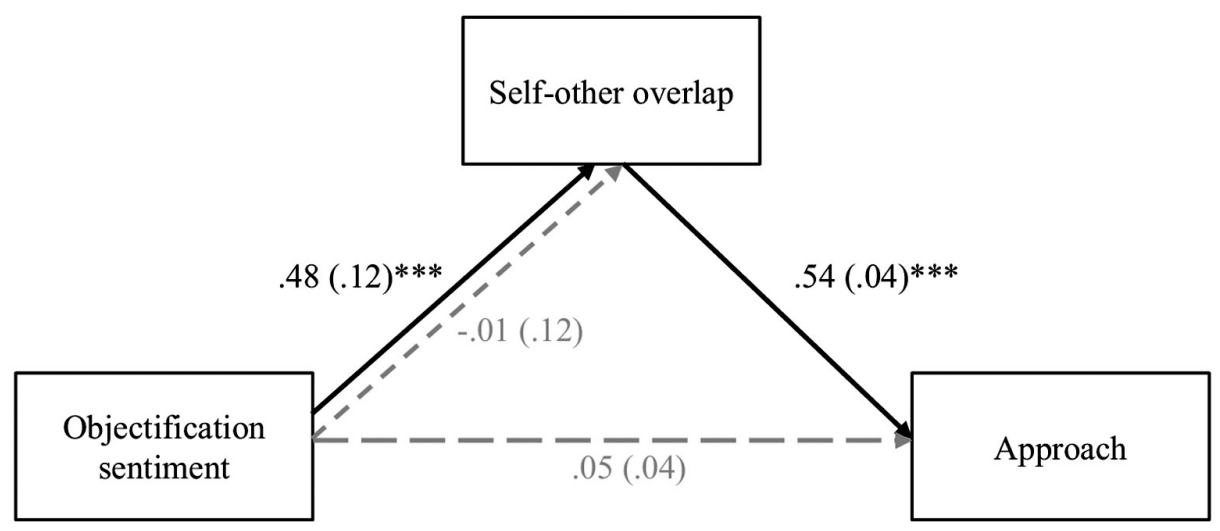

Fig. 3 Study 2 mediation analyses for the indirect effect of objectification sentiment on (a) perceived source warmth and (b) approach behavioral intentions through self-other overlap by condition. Unstandardized coefficients (standard errors). The values of the relation from objectification sentiment to self-other overlap outside the triangle represent the model in the complimentary objectification condition and the values inside the triangle represent the model in the critical objectification condition $* * * \mathrm{p}<.001$

and approach behaviors $[.0604, .4975]$ in the complimentary objectification condition did not. Consistent with hypotheses, objectification sentiment led to more positive source sentiment through the effect of objectification sentiment on self-other overlap when women reported complimentary objectification; however, source sentiment was not indirectly (or directly) influenced by objectification sentiment when women reported critical objectification. In sum, the results from Study 2 replicated those from Study 1. 


\section{General Discussion}

Objectification is a common form of sexism women experience that leads to myriad deleterious consequences (Fredrickson and Roberts 1997; see Roberts et al. 2018, for review). Research examining how women perceive those who objectify them has suggested opposing perceptions. Whereas some work has found that women negatively perceive objectifying sources (Teng et al. 2015), other research simultaneously has revealed that women desire future interactions with objectifying sources (Gervais et al. 2011). The current work extends this previous literature examining how women perceive male objectifying sources by manipulating valence of the reported experience and measuring consistency with attitudes toward sexualization. In line with hypotheses, reports of complimentary objectification led to more positive source sentiment than reports of critical objectification. This finding reveals a more nuanced picture as to how women perceive objectifying sources, suggesting that not all objectification is perceived equally. Given that previous work examining the role of objectification valence has focused primarily on weight (e.g., Calogero et al. 2009), these findings demonstrate the importance of considering valence of women's objectification experiences that focus explicitly on sex appeal.

In addition to valence, increased perceptions of self-other overlap with the source were predictive of more positive source sentiment. This finding is consistent with hypotheses and research on cognitive consistency (e.g., balance theory; Heider 1958), revealing that we report greater liking for others with similar views. Moreover, because self-objectification occurs when women internalize another's perspective of their sexualized body and body parts (Fredrickson and Roberts 1997), this measure of self-other overlap is a useful way to assess self-objectification in which women are sharing a perspective of their appearance with the source of objectification (Calogero 2012; Gervais et al. 2018). Although previous work has revealed that objectification valence and sentiment toward one's appearance predict selfother overlap on perceptions of appearance (Gervais et al. 2018), the current work extends this finding to reveal that objectification valence and objectification sentiment interact to predict generally perceived closeness with objectifying sources. Moreover, because a majority of 
participants wrote about an objectifying experience from an unknown source, the current work extends Gervais et al.' (2018) findings from known co-workers as sources of objectification to mostly unknown male sources.

Importantly, objectification sentiment moderated the link between objectification valence and source sentiment. In support of hypotheses, complimentary objectification caused less negative source sentiment, but only for women who reported that they enjoyed being sexualized. Likewise, objectification sentiment predicted source warmth and approach, but only in the complimentary objectification condition, not in the critical objectification condition. Importantly, perceived source warmth and approach intentions toward objectifying sources were relatively low for all women, but for women with more positive objectification sentiment, these sentiments were less negative relative to women with less positive objectification sentiment. This finding extends and challenges assumptions in previous work on objectification and women's enjoyment of sexualization by revealing that not all objectification is perceived equally negatively and that individual differences shape women's perceptions. The original proposition of objectification theory suggests that "Certainly not all women experience and respond to sexual objectification in the same way. Unique combinations of ethnicity, class, sexuality, age, and other physical and personal attributes undoubtedly create a unique set of experiences across women ...” (Fredrickson and Roberts 1997, p. 174). Yet, despite this acknowledgment of the importance women's diverse perspectives may play in determining perceptions of objectifying sources, few studies have examined predictors of positive (or at least negative) experiences of objectification. For example, for women who fit cultural ideals of beauty, objectification may be more positively perceived because the sexualization they experience may be more likely to take on a complimentary tone.

Shedding light on the potential mechanisms of this effect, the present work explored whether objectification valence also predicted consistency concerning overlap between self and other views. Consistent with hypotheses, reporting complimentary objectification caused more self-other overlap, but only for those who enjoyed being sexualized. Providing evidence for self-other overlap as a mechanism of women's more positive source perceptions, self-other overlap was a significant 
mediator, with a significant indirect effect of self-other overlap emerging for the link between objectification sentiment and warmth and approach in the complimentary objectification condition.

The current work provided another test of Gervais et al.' (2018) Balanced Objectification Hypothesis (BOH); in their original proposition, they identified perceived appearance self-other overlap as a mechanism to predict source sentiment from objectification valence. The findings from the current work support the tenants of the $\mathrm{BOH}$ using a new manipulation of objectification valence as well as extending the $\mathrm{BOH}$ to a novel individual difference variable-women's enjoyment of sexualization. Although the present study is one of the first to apply consistency motives to women's responses to sexual objectification (cf. Gervais et al. 2018), our findings share a likeness to the important work conducted by Calogero et al. (2009) revealing that positive perceptions of appearance compliments or negative perceptions of appearance criticisms led women to experience increased self-objectification. Our use of a cognitive consistency framework to understand women's responses to objectification is a novel contribution in and of itself, and it also illuminates a possible mechanism for understanding how relatively similar instances of objectification can sometimes be perceived negatively (Teng et al. 2015), while at other times increase desired interactions with the source (Gervais et al. 2011). Although objectification sentiment predicted perceived source perceptions, future work should explore other contextual factors of objectifying interactions that could shape perceived self-other overlap.

\section{Limitations and Future Directions}

Despite these contributions, our work is not without limitations. In particular, the current work relied upon the use of a vignette asking participants to recall or imagine a hypothetical experience of objectification adapted from Calogero (2013).A descriptive analysis of the written responses revealed that participants wrote primarily about remembered experiences; however, reliance upon this methodology has some limitations because participants have had time to distance themselves from both the experience and source, potentially modifying their original perceptions of the experience. Furthermore, we 
knew little about the context in which the objectification occurred beyond the information provided by the participant. Although experiences of complimentary or critical objectification may lead to similar source perceptions regardless of context, some instances may be important to consider.

Future work could expand upon our findings by creating objectifying experiences within a laboratory environment using a trained confederate to better control the source of objectification, as well as to assess real-time perceptions. Consistent with the present work, Kimble et al. (2016) found that women who enjoyed sexualization found objectification to be less sexually harassing than women who did not. Although we included a wider age range of participants than past studies examining the consequences of women's enjoyment of sexualization, future work should also strive to be more inclusive of women from various backgrounds (e.g., socioeconomic status, race, gender identity) and provide direct tests of how intersectional identities impact objectification perceptions and experiences (Williams and Fredrick 2015). Our study is one of few to give a nod to the notion that women's identities influence their perceptions of objectification (cf. Comiskey et al. 2019; Watson et al. 2012), and continued research is needed to further consider women's intersectional identities.

\section{Practice Implications}

The findings from our work suggest that women's experiences of objectification have consequences beyond the initial interaction. For many women, sources of objectification are perceived in a negative light (Teng et al. 2015). A majority of previous research on women's experiences of objectification assumes that women perceive these experiences negatively due to their numerous negative consequences (Roberts et al. 2018). Yet, for some women sexualized attention is a more favorable experience (Berdahl and Aquino 2009; Liss et al. 2011). Importantly, our findings paint a more nuanced image of women's objectifying experiences. Although women's perceptions of sources as more or less negative may seem relevant only to the interaction at the moment, women's responses as a result of these perceptions may ultimately shape with whom and how they interact in future interactions. 
In line with previous research on sexism, our work may suggest that complimentary forms of objectification are more insidious for women than their critical counterparts. Sexist ideology is categorized within two types: Whereas overt antipathy for women is identified as hostile sexism, the more seemingly benign yet restrictive form of sexism is identified as benevolent sexism (Glick and Fiske 1996). Our results suggest that similar to these distinctions of ambivalent sexism, not all forms of objectification are created equal. Instead, women report experiences that have different tones and, as identified within our study, different consequences for how they perceive the source (Hopkins-Doyle et al. 2019). In a study examining the effect of exposure to sexist ideology on women's engagement in self-objectification, more exposure to the more seemingly benign forms of benevolent sexism, but not hostile sexism, led to increased self-objectification (Calogero and Jost 2011). Furthermore, greater exposure to benevolent sexism leads women to engage in more system justification of the status quo (Jost and Kay 2005). In a world where women perceive equally sexist experiences of benevolent sexism and complimentary objectification as less sexist than hostile sexism (Riemer et al. 2014), experiences of complimentary objectification may be more sinister for women through the way in which their subjectively positive messages increase women's likelihood to approve of and support their subordinate status.

Some scholars and self-sexualizing women alike have argued that women's enjoyment of sexualization acts as a source of female empowerment accompanying third wave feminism (Attwood 2007; Baumgardner and Richards 2004; Levy 2005; Regehr 2012). Although sexualized attention may boost the confidence of women whose self-worth is contingent upon their appearance (Moffitt and Szymanski 2011), this heightened self-esteem appears rather fleeting with no long-term benefits (Breines et al. 2008). Although women's enjoyment of sexualization may be perceived as empowering, men's approval lies at the core of the women's sexualization. Instead, women who enjoy or even seek out sexual attention are doing so in the eye of male perceivers, suggesting women high in enjoyment of sexualization are inadvertently justifying a restrictive, not empowering, system. Women who perceive sources of complimentary objectification less negatively because they enjoy sexualization report acting in ways that reveal their approval. Whereas women who perceive an objectifying source 
negatively because they do not enjoy sexualization may engage in behaviors attempting to minimize future interactions with the source. For example, in the current study, participants reported ignoring, distancing, and occasionally confronting sources of objectification. Although women's reactance to being a target of objectification can lead to increased backlash and harsher treatment, these women may be less likely to encounter objectification from this same person in the future. In comparison, the consequences of women's approving behaviors may increase the likelihood of the source objectifying her again in the future relative to women who show disapproval toward objectifying sources. Thus, the current findings suggest that increasing women's awareness of the unadvertised costs of objectification may help diminish women's future objectifying experiences as well as their appearance contingencies of self-worth.

\section{Conclusion}

The social rewards of acting positively toward another person are difficult to contradict-to be sure, "you can attract more flies with honey than vinegar." In the present work, we have suggested that source sentiment relies, at least in part, on perceptions of positive or negative objectification valence as a predictor of social consequences to approach or avoid the source of objectification. Although some instances of objectification appear more positive, all instances of objectification serve to strip women of their personhood, and thus it remains possible that the same men who engage in complimentary objectification (i.e., rewarding women for conforming to femininity) engage in critical objectification (i.e., punishing women for not conforming to femininity), so that ultimately they are perceiving all women through an objectifying lens. The current work reveals that women's perceptions of objectifying sources depend on the valence of the objectifying experience as well as women's attitude about being sexualized, with women with more positive objectification sentiment perceiving sources of complimentary objectification more positively. Importantly, perceptions have the potential to shape women's future interactions, and like flies to "honey," the valence of experiences may interact with attitudes about sexualization to increase the possibility of experiencing objectification 
in the future. The sweet allure of "honey" must be carefully deconstructed in order to challenge the social structure and change the way that women's bodies are objectified in social situations.

Acknowledgments Abigail R. Riemer, Department of Life Sciences, Carroll University; Jill Allen, Department of Psychology, Drake University; Marco Gullickson, Department of Educational Psychology, University of Nebraska-Lincoln; Sarah J. Gervais, Department of Psychology, University of Nebraska-Lincoln. Study 1 was conducted as the third author's undergraduate thesis. Additionally, these studies were funded by a grant from the University of Nebraska Department of Psychology and Office of Research to the last author.

Compliance with Ethical Standards All of the research reported in the manuscript complies with APA ethical standards in the treatment of human participants. The Institutional Review Board of the University of Nebraska-Lincoln at which this study was conducted approved of the study and informed consent procedures.

\section{References}

Aiken, L. S., \& West, S. G. (1991). Multiple regression: Testing and interpreting interactions. Thousand Oaks, CA: Sage Publications, Inc..

Aron, A., Aron, E. N.,\& Smollan, D. (1992). Inclusion of other in the self scale and the structure of interpersonal closeness. Journal of Personality and Social Psychology, 63, 596-612. https://doi.org/10.1037/0022-3514.63.4.596

Attwood, F. (2007). Sluts and riot grrrls: Female identity and sexual agency. Journal of Gender Studies, 16, 233-247. https://doi. org/10.1080/09589230701562921

Barreto, M., \& Ellemers, N. (2005). The burden of benevolent sexism: How it contributes to the maintenance of gender inequalities. European Journal of Social Psychology, 35, 633-642. https://doi.org/10.1002/ejsp.270

Bartky, S. L. (1990). Femininity and domination: Studies in the phenomenology of oppression. New York: Routledge.

Baumgardner, J., \& Richards, A. (2004). Feminism and femininity: We learned to stop worrying and love the thong. In A. Harris (Ed.), All about the girl: Culture, power, and identity (pp. 59-68). New York: Routledge.

Berdahl, J. L., \& Aquino, K. (2009). Sexual behavior at work: Fun or folly? Journal of Applied Psychology, 94, 34-47. https://doi.org/10.1037/a0012981

Biernat, M., \& Crandall, C. S. (1999). Racial attitudes. In J. P. Robinson, P. R. Shaver, \& L. S. Wrightsman (Eds.), Measures of social psychological attitudes: Measures of political attitudes (Vol. 2, pp. 297-411). San Diego, CA: Academic Press. 
Bogardus, E. S. (1933). A social distance scale. Sociology and Social Research, 17, 265-271.

Breines, J. G., Crocker, J.,\& Garcia, J. A. (2008). Self-objectification and well-being in women's daily lives. Personality and Social Psychology Bulletin, 34, 583-598. https://doi.org/10.1177/0146167207313727

Brewer, M. B., Brown, R. J., Gilbert, D. T., Fiske, S. T., \& Lindzey, G. (1998). The handbook of social psychology. New York: Oxford University Press.

Broccoli, T. L. (2008). Relationship between self and physical body: An examination of the phenomenon of disconnect. New Brunswick, NJ: Rutgers The State University of New Jersey-New Brunswick.

Calogero, R. M. (2012, April). Objects don't object: An integrative systemjustification perspective on objectification. In 6oth Nebraska motivation symposium: What do teddy bears and strippers have in common? The motivational antecedents and consequences of humanizing nonhuman agents and dehumanizing human agents. (chair: Sarah Gervais). University of Nebraska-Lincoln.

Calogero, R. M. (2013). Objects don't object: Evidence that self-objectification disrupts women's social activism. Psychological Science, 24, 312-318. https:// doi.org/10.1177/0956797612452574

Calogero, R. M., \& Jost, J. T. (2011). Self-subjugation among women: Exposure to sexist ideology, self-objectification, and the protective function of the need to avoid closure. Journal of Personality and Social Psychology, 100, 211-228. https://doi.org/10.1037/aoo21864

Calogero, R. M., Herbozo, S., \& Thompson, J. K. (2009). Complimentary weightism: The potential costs of appearance-related commentary for women's self-objectification. Psychology of Women Quarterly, 33, 120-132. https://doi. org/10.1111/j.1471-6402.2008.01479.X

Comiskey, A., Parent, M. C., \& Tebbe, E. A. (2019). An inhospitable world: Exploring a model of objectification theory with transwomen. Psychology of Women Quarterly. https://doi.org/10.1177/0361684319889595

Earp, B. D., \& Trafimow, D. (2015). Replication, falsification, and the crisis of confidence in social psychology. Frontiers in Psychology, 6. https://doi. org/10.3389/fpsyg.2015.00621

Erchull, M. J., \& Liss, M. (2013). Feminists who flaunt it: Exploring the enjoyment of sexualization among young feminist women. Journal of Applied Social Psychology, 43, 2341-2349. https://doi.org/10.1111/jasp.12183

Faul, F., Erdfelder, E., Buchner, A., \& Lang, A. G. (2009). Statistical power analyses using $G^{*}$ power 3.1: Tests for correlation and regression analyses. Behavior Research Methods, 41, 1149-116o. https://doi.org/10.3758/BRM.41.4.1149

Festinger, L. (1957). A theory of cognitive dissonance. Palo Alto, CA: Stanford University Press.

Fiske, S. T., Cuddy, A. J. C., Glick, P.,\& Xu, J. (2002). A model of (often mixed) stereotype content: Competence and warmth respectively follow from perceived status and competition. Journal of Personality and Social Psychology, 82, 878-902. https://doi.org/10.1037/pspaoo00163. 
Fredrickson, B. L., \& Roberts, T. (1997). Objectification theory: Toward understanding women's lived experiences and mental health risks. Psychology of Women Quarterly, 21, 173-206. https://doi.org/10.1111/j.1471-6402.1997. tboo108.x

Gervais, S. J., Vescio, T. K., \& Allen, J. (2011). When what you see is what you get: The consequences of the objectifying gaze for women and men. Psychology of Women Quarterly, 35, 5-17. https://doi.org/10.1177/0361684310386121

Gervais, S. J., Allen, J., Riemer, A. R., \& Gullickson, M. (2018). The balanced objectification hypothesis: The effects of objectification valence and body sentiment on source sentiment. Personality and Social Psychology Bulletin, 45, 571-586. https://doi.org/10.1177/0146167218789625

Glick, P., \& Fiske, S. T. (1996). The Ambivalent Sexism Inventory: Differentiating hostile and benevolent sexism. Journal of Personality and Social Psychology, 70, 491-512. https://doi.org/10.1037/0022-3514.70.3.491

Hall, P. C., West, J. H., \& McIntyre, E. (2012). Female self-sexualization in myspace.com personal profile photographs. Sexuality and Culture, 16, 1-16. https://doi.org/10.1007/s12119-011-9095-0

Hayes, A. F. (2018). Introduction to mediation, moderation, and conditional process analysis: A regression-based approach (2nd ed.). New York: The Guilford Press.

Heider, F. (1958). The psychology of interpersonal relations. Hoboken, NJ: John Wiley.

Herbozo, S., \& Thompson, J. K. (2006). Appearance-related commentary, body image, and self-esteem: Does the distress associated with the commentary matter? Body Image, 3, 255-262. https://doi.org/10.1016/j. bodyim.2006.04.001

Holland, E., Koval, P., Stratemeyer, M., Thomson, F., \& Haslam, N. (2017). Sexual objectification in women's daily lives: A smartphone ecological momentary assessment study. British Journal of Social Psychology, 56, 314-333. https:// doi.org/10.1111/bjso.12152

Hopkins-Doyle, A., Sutton, R. M., Douglas, K. M., \& Calogero, R. M. (2019). Flattering to deceive: Why people misunderstand benevolent sexism. Journal of Personality and Social Psychology, 116, 167-192. https://doi.org/10.1037/ pspaooo0135

Inman, M. L., \& Baron, R. S. (1996). Influence of prototypes on perceptions of prejudice. Journal of Personality and Social Psychology, 70, 727-739. https:// doi.org/10.1037/0022-3514.70.4.727

Jost, J. T., \& Kay, A. C. (2005). Exposure to benevolent sexism and complementary gender stereotypes: Consequences for specific and diffuse forms of system justification. Journal of Personality and Social Psychology, 88, 498-509. https://doi.org/10.1037/0022-3514.88.3.498

Kilanski, S. E., \& Rudman, L. A. (1998). Wanting it both ways?: Do women approve of benevolent sexism? Sex Roles, 39, 333-352. https://doi. org/10.1023/A:1018814924402 
Kimble, K. M., Farnum, K. S., Wiener, R. L., Allen, J., Nuss, G. D., \& Gervais, S. J. (2016). Differences in the eyes of the beholders: The role of subjective and objective judgments in sexual harassment claims. Law and Human Behavior, 40, 319-336. https://doi.org/10.1037/lhbooo0182

Kozee, H. B., Tylka, T. L., Augustus-Horvath, C. L., \& Denchik, A. (2007). Development and psychometric evaluation of the Interpersonal Sexual Objectification Scale. Psychology of Women Quarterly, 31, 176-189. https://doi. org/10.1111/j.1471-6402.2007.00351.X

Levy, A. (2005). Female chauvinist pigs: Women and the rise of raunch culture. New York: Free Press.

Liss, M., Erchull, M. J., \& Ramsey, L. (2011). Empowering or oppressing? Development and exploration of the enjoyment of Sexualization scale. Personality and Social Psychology Bulletin, 37, 55-68. https://doi. org/10.1177/0146167210386119

Little, T. D., Card, N. A., Bovaird, J. A., Preacher, K. J., \& Crandall, C. S. (2007). Structural equation modeling of mediation and moderation with contextual factors. In T. D. Little, J. A. Bovaird, \& N. A. Card (Eds.), Modeling contextual effects in longitudinal studies (p. 207-230). New York: Lawrence Erlbaum Associates Publishers.

Mallinckrodt, B., Abraham, W. T., Wei, M., \& Russell, D. W. (2006). Advances in testing the statistical significance of mediation effects. Journal of Counseling Psychology, 53, 372-378. https://doi.org/10.1037/0022-0167.53.3.372

McLaren, L., Kuh, D., Hardy, R., \& Gauvin, L. (2004). Positive and negative bodyrelated comments and their relationship with body dissatisfaction in middleaged women. Psychology and Health, 19, 261-272. https://doi.org/10.1080/088 7044031000148246

Moffitt, L. B., \& Szymanski, D. M. (2011). Experiencing sexually objectifying environments: A qualitative study. The Counseling Psychologist , 39, 67-106. https://doi.org/10.1177/0011000010364551

Nowatzki, J., \& Morry, M. M. (2009).Women's intentions regarding, and acceptance of, self-sexualizing behavior. Psychology of Women Quarterly, 33, 95-107. https://doi.org/10.1111/j.1471-6402.2008.01477.x

Osgood, C. E., \& Tannenbaum, P. H. (1955). The principle of congruity in the prediction of attitude change. Psychological Review, 62, 42- 55. https://doi. org/10.1037/hoo48153

Puvia, E., \& Vaes, J. (2015). Promoters versus victims of objectification: Why women dehumanize sexually objectified female targets. Revue Internationale de Psycholgie Sociale, 28, 63-93.

Regehr, K. (2012). The rise of recreational burlesque: Bumping and grinding towards empowerment. Sexuality and Culture, 16, 134-157. https://doi. org/10.1007/s12119-011-9113-2

Riemer, A. R., Chaudoir, S. R., \& Earnshaw, V. (2014). What looks like sexism and why? The effect of comment type and perpetrator type on women's perceptions of sexism. The Journal of General Psychology, 141, 263-279. https://doi.org/10. 1080/00221309.2014.907769 
Roberts, T. A., Calogero, R. M., \& Gervais, S. J. (2018). Objectification theory: Continuing contributions to feminist psychology. In C. B.

Travis, J. W. White, A. Rutherford, W. S. Williams, S. L. Cook, \& K. F. Wyche (Eds.), APA handbooks in psychology series. APA handbook of the psychology of women: History, theory, and battlegrounds (pp. 249-271). Washington, DC: American Psychological Association. https://doi.org/10.1037/0000059-013

Shrout, P. E., \& Bolger, N. (2002). Mediation in experimental and nonexperimental studies: New procedures and recommendations. Psychological Methods, 7, 422445. https://doi.org/10.1037/1082-989X.7.4.422

Snyder, M., Tanke, E. D., \& Berscheid, E. (1977). Social perception and interpersonal behavior: On the self-fulfilling nature of social stereotypes. Journal of Personality and Social Psychology, 35, 656-666. https://doi. org/10.1037/0022-3514.35.9.656

Swann, W. B., Pelham, B. W., \& Krull, D. S. (1989). Agreeable fancy or disagreeable truth? Reconciling self-enhancement and self-verification. Journal of Personality and Social Psychology, 57, 782-791. https://doi. org/10.1037/0022-3514.57.5.782

Swim, J. K., Hyers, L. L., Cohen, L. L., \& Ferguson, M. J. (2001). Everyday sexism: Evidence for its incidence, nature, and psychological impact from three daily diary studies. Journal of Social Issues, 57, 31-53. https://doi. org/10.1111/0022-4537.00200

Tantleff-Dunn, S., Thompson, J. K., \& Dunn, M. E. (1995). The Feedback on Physical Appearance Scale (FOPAS): Questionnaire development and psychometric evaluation. Eating Disorders, 3, 341-350. https://doi. org/10.1080/10640269508250063

Teng, F., Chen, Z., Poon, K., \& Zhang, D. (2015). Sexual objectification pushes women away: The role of decreased likeability. European Journal of Social Psychology, 45, 77-87. https://doi.org/10.1002/ejsp.2070

Watson, L. B., Robinson, D., Dispenza, F., \& Nazari, N. (2012). African American women's sexual objectification experiences: A qualitative study. Psychology of Women Quarterly, 36, 458-475. https://doi.org/10.1177/0361684312454724

Williams, S. L., \& Fredrick, E. G. (2015). One size may not fit all: The need for a more inclusive and intersectional psychological science on stigma. Sex Roles, 73, 384-39o. https://doi.org/10.1007/s11199-015-0491-z

Williams, J., \& MacKinnon, D. P. (2008). Resampling and distribution of the product methods for testing indirect effects in complex models. Structural Equation Modeling: A Multidisciplinary Journal, 15, 23-51. https://doi.org/10.1 o80/10705510701758166 
Online supplement for Riemer, A. R., Allen, J., Gullickson, M., and Gervais, S. J. (2020). "You can catch more flies with honey than vinegar": Objectification valence interacts with women's enjoyment of sexualization to influence social perceptions. Sex Roles. Abigail R. Riemer, Carroll University. E-mail: abbeyriemer@gmail.com

\section{Study 1 Method}

Prior to completing the manipulation of objectification valence, participants completed a manipulation of body satisfaction. Specifically, participants were asked to compare their appearance to a pictured woman by listing three ways in which the pictured woman was either more (low body satisfaction condition; first woman pictured below) or less (high body satisfaction condition; second woman pictured below) attractive than themselves. Immediately following this manipulation, participants completed a body satisfaction manipulation check.

\section{Measures}
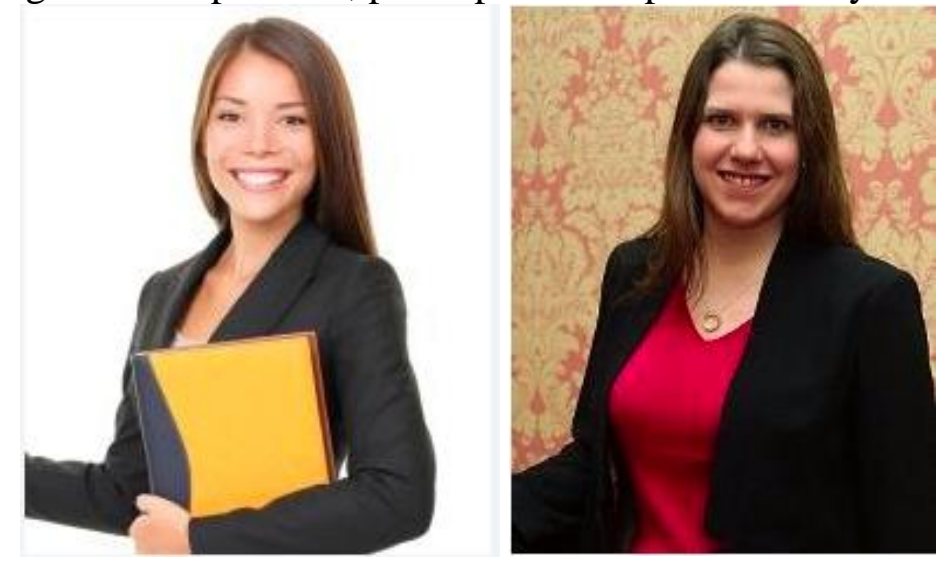

Body satisfaction. Immediately following the body satisfaction manipulation, participants were asked to indicate their satisfaction with their attractiveness. Specifically, participants were asked to indicate "How positively do you feel about your body right now?" and "How attractive do you think you are right now?" using a 1 (not at all) to 5 (extremely) scale. Responses to the two items were averaged $(M=2.79, S D=1.08, \alpha=.87)$ with higher values indicating more body satisfaction.

Body shame. As a measure of body shame, participants completed the body shame subscale of the Objectified Body Consciousness Scale (OBCS; McKinley \& Hyde, 1996). This 8-item measure asks participants to rate their agreement with statements regarding how they feel about their appearance. For instance, participants are asked to rate their agreement with items like, "I feel ashamed of myself when I haven't made the effort to look my best" and "When I can't control my weight, I feel like there is something wrong with me." Participants rated their agreement using a 1 (strongly disagree) to 6 (strongly agree), with the option of "not applicable." Not applicable choices were coded as missing, appropriate items were reverse coded, and means were created $(M=3.52, S D=1.13, \alpha=.82)$, with higher values indicating greater feelings of body shame.

Source competence. Participants were also asked to indicate how competent the source seemed (i.e., competent, confident, independent, and intelligent) on a 1 (not at all) to 5 (extremely) Likert-type scale (Fiske et al., 2002). Mean competence scores were created $(\alpha=.87$, $M=2.62, S D=1.12$ ) with higher scores indicating more competence. 


\section{Results}

Body shame and satisfaction. Participants' feelings of body satisfaction and body shame were submitted to separate body satisfaction (positive, negative) $t$-tests. There was no significant effect of the manipulation on participants' feelings of body satisfaction, $t(119)=-1.32, p=.19, d$ $=.24$, nor was there a significant effect of the manipulation on participants' feelings of body shame, $t(119)=0.24, p=.81, d=.04$. Participants in the negative body satisfaction condition reported similar levels of body satisfaction $(M=2.67, S D=1.10)$ and body shame $(M=3.54, S D$ $=1.10$ ) as women in the positive body satisfaction condition (satisfaction $M=2.93, S D=1.06$; shame $M=3.49, S D=1.19$ ).

Source Competence. A main effect of condition on perceived source competence emerged, $t(119)=-3.95, p<.001, d=.72$; women in the complimentary objectification condition perceived the objectifying source as more competent $(M=2.97, S D=1.08)$ than women in the critical objectification condition $(M=2.21, S D=1.03)$. Step 2 of the model was significant on perceived source competence, $F(3,117)=8.634, p<.0001, R^{2}=.18$. The objectification sentiment $X$ objectification valence interaction was significant, $b=.39, S E=.15, t(117)=2.55, p$ $=.012$; objectification sentiment predicted competence in the complimentary objectification condition, $b=.31, S E=.10, t(117)=2.97, p=.004$, but it was unrelated to competence in the critical objectification condition, $b=-.08, S E=.11, t(117)=-0.72, p=.47$. To further consider the interaction between objectification sentiment and objectification valence, we compared condition differences at higher $(+1 S D)$ and lower $(-1 S D)$ levels of objectification sentiment. The difference between complimentary and critical objectification was significant at higher, $b=$ $1.24, S E=.26, t(117)=-4.70, p<.0001$, but not lower, $b=.-.28, S E=.26, t(117)=-1.07, p=$ .29 , levels of objectification sentiment.

Finally, we examined the indirect effects of objectification sentiment on competence via self-other overlap for complimentary versus critical objectification conditions. The $95 \%$ confidence interval in the critical objectification condition contained zero [-.0543, .0235], whereas the $95 \%$ confidence interval in the complimentary objectification $[.0428, .3111]$ did not. Objectification sentiment indirectly led to more perceptions of source competence through an increased perception of similarity with the source when women reported experienced complimentary objectification; however, source competence was not indirectly (or directly) influenced by objectification sentiment when women reported experienced critical objectification.

\section{Study 2 Method and Results}

The same measure of competence used in the Study 1, was again used in Study 2 ( $\alpha=$ $.92, M=2.44, S D=1.28)$. A main effect of condition on perceived competence emerged, $t(108)$ $=-2.71, p=.008$; women in the complimentary objectification condition perceived the source as more competent $(M=2.74, S D=1.30)$ than women in the critical objectification condition $(M=$ $2.09, S D=1.18)$. Step 2 of the model was significant on source competence, $F(3,106)=3.64, p$ $=.015, R^{2}=.09$. The objectification sentiment $\mathrm{X}$ objectification valence interaction did not reach conventional levels of significance, $b=.315, \mathrm{SE}=.20, \mathrm{t}(106)=1.59, \mathrm{p}=.115$. However, exploring this trend revealed that objectification sentiment was associated positively with competence in the complimentary objectification condition, but this effect did not reach conventional levels of significance, $b=.25, \mathrm{SE}=.14, \mathrm{t}=1.81, \mathrm{p}=.07$. Objectification sentiment was unrelated to competence in the critical objectification condition, $\mathrm{b}=-.07, \mathrm{SE}=.14, \mathrm{t}=-.46$, $\mathrm{p}=.65$. Also, the difference between complimentary and critical objectification was significant at higher, $\mathrm{b}=1.04$, SE .33, $\mathrm{t}(106)=3.11, \mathrm{p}=.0024$, but not lower, $\mathrm{b}=.28, \mathrm{SE} .34, \mathrm{t}(106)=.84$, 
$\mathrm{p}=.40$, levels of objectification sentiment.

Like in Study 1, the 95\% confidence intervals in the critical objectification condition [$.0337, .0153$ ] contained zero, whereas the $95 \%$ confidence intervals for the complimentary objectification condition [.0383, .4182] did not. Objectification sentiment led to more perceived source competence through the effect of objectification sentiment on self-other overlap when women reported experienced complimentary objectification; however, competence was not indirectly (or directly) influenced by objectification sentiment when women reported experienced critical objectification.

Table 1s

Competence as a function of objectification valence and objectification sentiment.

\begin{tabular}{lcccc}
\hline Study 1 & & & & \\
\hline Step 1 & $b$ & $S E$ & $t$ & $p$ \\
(Constant) & 2.08 & .18 & 11.89 & .0001 \\
Objectification valence & 0.67 & .24 & 2.78 & .006 \\
Objectification sentiment & 0.10 & .10 & 0.97 & .334 \\
Step 2 & & & & \\
(Constant) & 2.09 & .17 & 12.05 & .0001 \\
Objectification valence & 0.66 & .24 & 2.79 & .006 \\
Objectification sentiment & -0.07 & .14 & -.46 & .650 \\
Objectification valence x objectification sentiment & 0.32 & .20 & 1.59 & .115 \\
\hline Study 2 & & & & \\
\hline Step 1 & $b$ & $S E$ & $t$ & $p$ \\
(Constant) & 2.21 & .14 & 15.80 & .0001 \\
Objectification valence & 0.76 & .19 & 4.00 & .0001 \\
Objectification sentiment & 0.13 & .08 & 1.65 & .102 \\
Step 2 & & & & \\
(Constant) & 2.21 & .14 & 16.18 & .0001 \\
Objectification valence & 0.76 & .19 & 4.09 & .0001 \\
Objectification sentiment & -0.08 & .11 & -.72 & .473 \\
Objectification valence x objectification sentiment & 0.39 & .15 & 2.55 & .012 \\
\hline
\end{tabular}




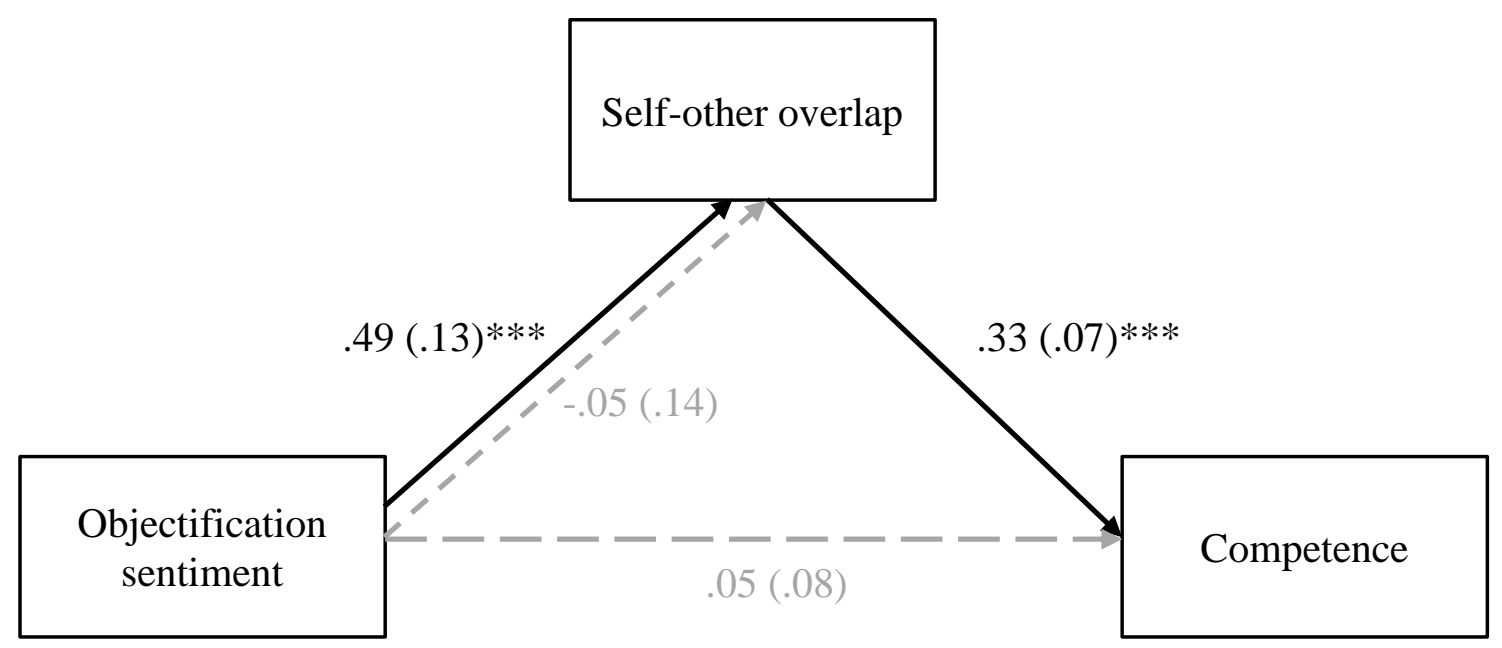

Figure 1s. Mediation analyses for the indirect effect of objectification sentiment on competence through self-other overlap by condition for Study 1. Unstandardized coefficients (standard errors). The values of the relation from objectification sentiment to self-other overlap outside the triangle represent the model in the complimentary objectification condition and the values inside the triangle represent the model in the critical objectification condition.

$* * * p<.001$.

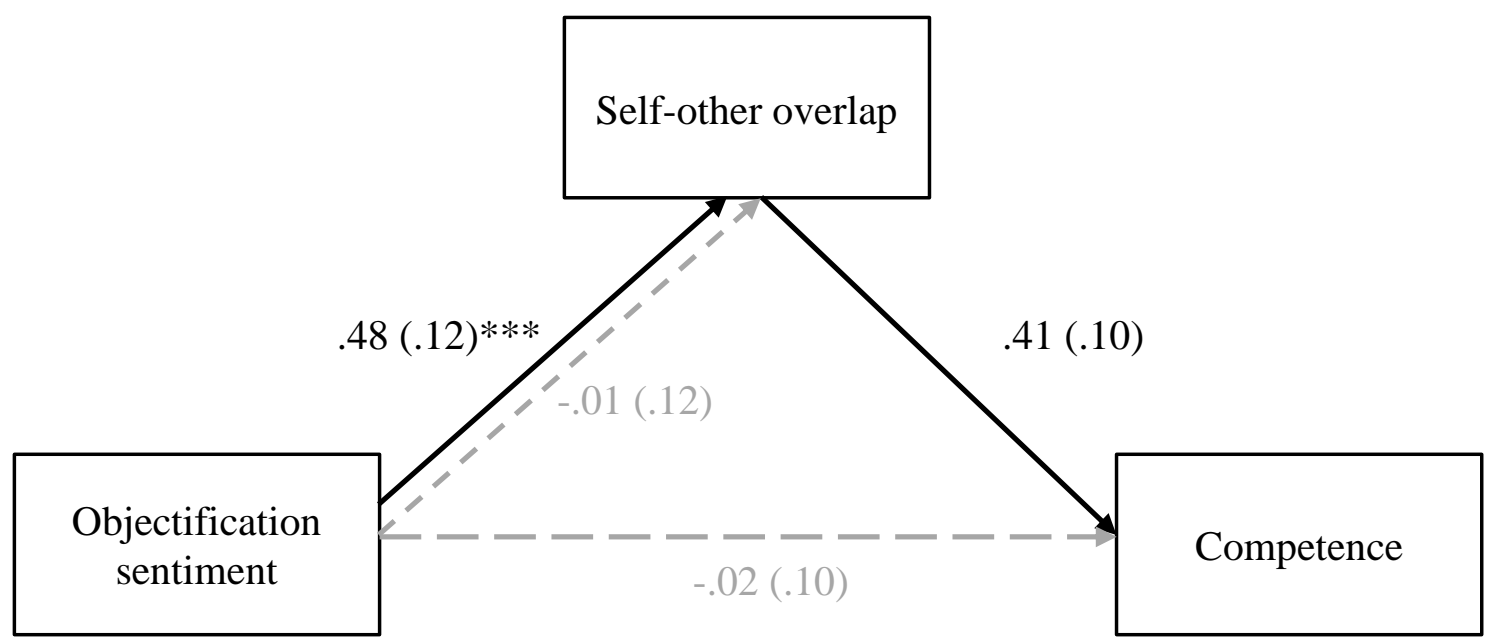

Figure 2 s. Mediation analyses for the indirect effect of objectification sentiment on competence through self-other overlap by condition for Study 2. Unstandardized coefficients (standard errors). The values of the relation from objectification sentiment to self-other overlap outside the triangle represent the model in the complimentary objectification condition and the values inside the triangle represent the model in the critical objectification condition.

$* * * p<.001$. 